\title{
RECYCLING OF WASTE PRODUCTS : A GREEN INITIATIVE
}

\author{
S. Ubale ${ }^{1}$, S. Joshi \\ Dharampeth M. P. Deo Memorial Science College, Nagpur. \\ Corresponding author Email address- seemaksu@yahoo.co.in
}

\begin{abstract}
In India major part of electrical power is supplied through the thermal power plants $(52 \%)$. Thermal power plants use coal for producing thermal energy. After burning of coal, it reduces to two types of ash, 1 fly ash and 2 bottom ash. The quantity of fly ash is huge as compared to the bottom ash. The disposal of this fly ash is a major problem. Government has taken many measures for the disposal of the ash. The ash contains silica and alumina in large proportion. Here in this work the fly ash is recycled into some value added product.
\end{abstract}

The fly ash is composed with the sodium hydroxide, calcium hydroxide and then compressed in a hydraulic press by applying different pressures. The resultant is allowed to dry. Very hard discs are prepared. The density and thermal conductivity of the discs are measured. It is found to be a bad conductor of heat. The density of the samples shows variation in density and thermal conductivity with change in the applied pressure.

Key words :Recycling, Fly ash, thermal conductivity, density

\section{Introduction}

The power generated by the thermal power plants is around $54 \%$ of the total power generation in India. The thermal power is derived from burning of the coal. There are two types of coal ash produced in coal based thermal power plants, i.e. fly ash and bottom ash.

In the process of thermal power generation the country is producing huge amount of fly ash and with the increase of the quantum of the thermal power generation the production of this ash will be more than double. In India, major problems faced by coal based thermal power plants are the handling and disposal of fly ash ${ }^{1}$.

Fly ash occurs as very fine spherical particles and is the residue of combustion of coal-originally a mixture of vegetation, clay and comprises a wide range of inorganic particles. The principal constituents of ash are silica, alumina and iron oxide. The fly ash possesses Pozzolanic or cementitious property in nature i. e. it solidifies and becomes hard and strong after exposure to humidity. Thus the fly ash can be recycled and 
compounded with suitable inorganic chemicals into a hard and strong tiles. After thorough study it can be developed into a product of utility on commercial basis $^{2}$. This will be recycling of the waste material,' a green initiative'.

Experimental- The fly ash used in this work is obtained from the Khaparkheda thermal power plant. The ash was subjected to chemical analysis. The report of the same is presented in Table 1 (Anacon laboratories Pvt. Ltd.).

This fly ash was mixed with calcium hydroxide and sodium hydroxide in fixed proportion (3:2:1 weight proportion respectively). The powder was thoroughly mixed in an aget mortar with the help of pestle for half an hour. The powder was placed in a suitable mould and pressure was applied by a hydraulic press (Kimaya Engineering, Thane).

Different samples were prepared for the same composition by applying different pressures.

The samples are round circular discs of varying thickness and of fixed diameter.

The density of each sample is determined by finding out its mass and volume of the sample.

The thermal conductivity of the sample is determined on a thermal conductivity apparatus. Divided bar method is generally used for measuring thermal conductivity of poor conductors in solids. The apparatus works on the principle of divided bar method $^{3}$. The values of density and thermal conductivity for different pressures thus obtained are presented in Table2.

Table 1 Major oxides present in the fly ash

\begin{tabular}{|c|c|c|}
\hline S.No. & Components & $\%$ \\
\hline 1 & Silica & 55.81 \\
\hline 2 & Aluminium oxide & 25.41 \\
\hline 3 & Iron oxide & 9.35 \\
\hline
\end{tabular}

Rest $10 \%$ is composed of Titanium dioxide(o.28), Manganese oxide(0.21), Magnesium oxide(1.18), Calcium oxide(1.28), Potassium oxide(1.28), Sodium oxide(0.96), loss on ignition(1.82), moisture (0.03). 
Table 2

\begin{tabular}{|c|c|c|l|}
\hline Sample no. & Pressure in tons & Density $\left(\mathrm{gm} / \mathrm{cm}^{3}\right)$ & thermal cond. \\
\hline 1 & 9 & 1.61 & $0.85 \times 10^{-3}$ \\
\hline 2 & 8.5 & 1.56 & $0.55 \times 10^{-3}$ \\
\hline 3 & 8 & 1.58 & $1.07 \times 10^{-3}$ \\
\hline 4 & 7.5 & 1.69 & $1.44 \times 10^{-3}$ \\
\hline 5 & 7 & 1.57 & $1.03 \times 10^{-3}$ \\
\hline
\end{tabular}

Result and Discussion- The graph 1 shows variation of the density with respect to applied pressure. The graph 2 is drawn between thermal conductivity and applied pressure..

The thermal conductivity and the density are maximum for the sample No. 4 which is prepared by applying a pressure of 7.5 tons. The values of density and thermal conductivity are minimum for the sample no.2.

Thermal conductivity can be related with the density of the sample. High density samples are showing higher value for the thermal conductivity. Inverse of thermal conductivity is thermal resistance. Small value of thermal conductivity means higher value of thermal resistance. The material can be developed into a thermal insulator which can be used in the construction of buildings for thermal insulation purpose. The material is under consideration and needs to be studied very rigorously for its other physical properties such as density, volume electrical as well as dielectric properties. It needs to be studied from viability point of view i.e. economy and mass production feasibility. This is a recycling of waste product obtained from thermoelectric power plant thus it is very important from environment protection point of view. Presently out of the total ash generated by the thermo electric power plants, only around $50 \%$ is utilized. Government of India and the department of Science and Technology are taking special efforts. This is a very small attempt to provide an answer to the problem. 
Figure 1

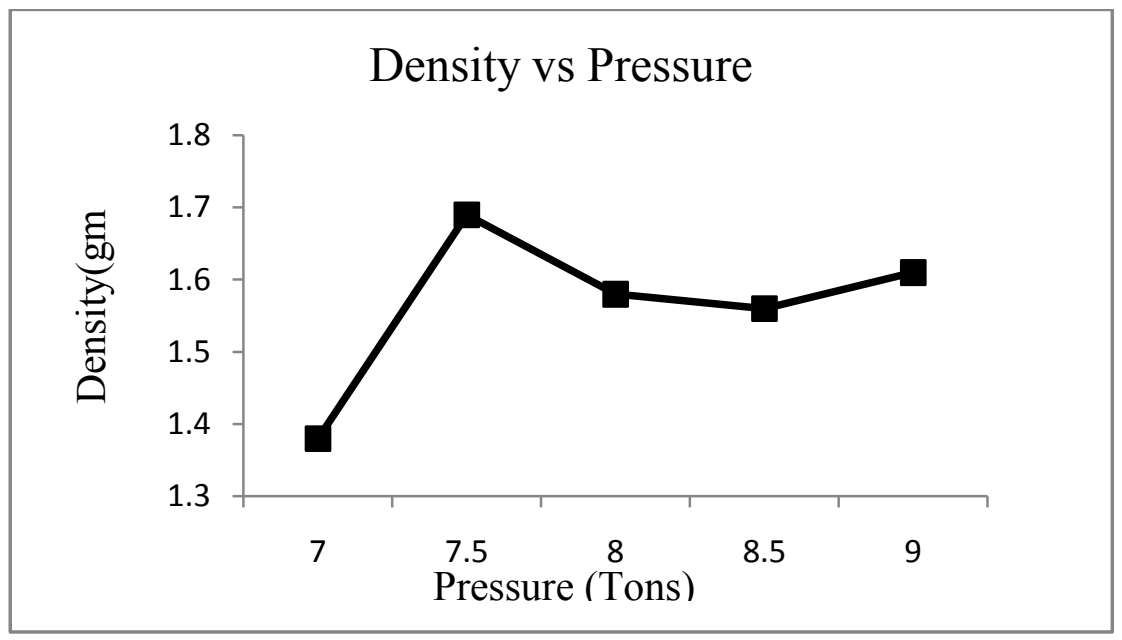

Figure 2

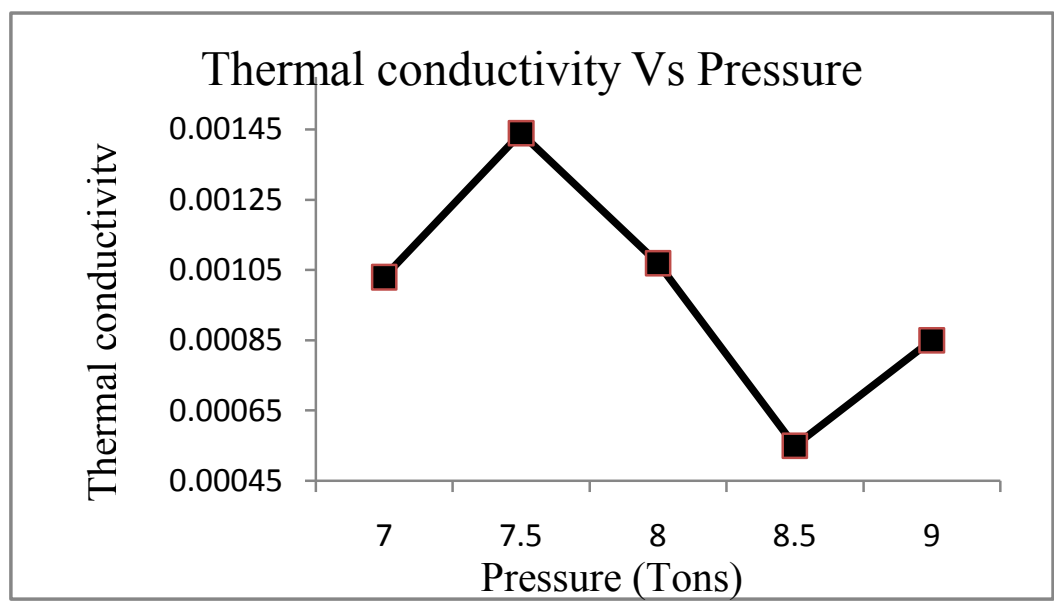

\section{References}

Arvind Kumar Rai1, Biswajit Paul and Gurdeep Singh (2010) Journal of Advanced Laboratory Research in Biology,volume I, Issue II, October 2010

Suhas V. Patil, Suryakant C. Nawle , and Sunil J. Kulkarni, (2013). International Journal of Science, Engineering and Technology Research (IJSETR) Volume 2, Issue 9, September 2013.

S. K. Ubale, C.S. Adgaonkar, and M.R. Deole, (1998). Physis Education JulySeptember, 117-120. 